https://helda.helsinki.fi

\title{
Instability of the Sb vacancy in GaSb
}

\section{Segercrantz, N.}

2017-05-03

Segercrantz , N , Slotte , J , Tuomisto , F , Mizohata , K \& Räisänen , J 2017 , ' Instability of the Sb vacancy in GaSb ' , Physical Review B , vol. 95 , no. 18 , 184103 . https://doi.org/10.1103/PhysRevB.95.1841

http://hdl.handle.net/10138/187066

https://doi.org/10.1103/PhysRevB.95.184103

cc_by

publishedVersion

Downloaded from Helda, University of Helsinki institutional repository.

This is an electronic reprint of the original article.

This reprint may differ from the original in pagination and typographic detail.

Please cite the original version. 


\title{
Instability of the Sb vacancy in GaSb
}

\author{
N. Segercrantz, J. Slotte, and F. Tuomisto \\ Department of Applied Physics, Aalto University School of Science, P.O. Box 15100, FIN-00076 Aalto, Finland
}

K. Mizohata and J. Räisänen

Department of Physics, University of Helsinki, P.O. Box 43, FI-00014 University of Helsinki, Finland

(Received 18 November 2016; revised manuscript received 30 March 2017; published 3 May 2017)

\begin{abstract}
We demonstrate that the instability of the Sb vacancy in GaSb leads to a further increase in the acceptor-type defect concentration in proton irradiated undoped, $\mathrm{p}$-type GaSb. Using positron annihilation spectroscopy in situ with $10 \mathrm{MeV}$ proton irradiation at $35 \mathrm{~K}$, we find that the irradiation produces both native vacancy defects in $\mathrm{GaSb}$. However, the $\mathrm{Sb}$ vacancy is unstable above temperatures of $150 \mathrm{~K}$ and undergoes a transition resulting in a Ga vacancy and a Ga antisite. The activation energy of this transition is determined to be $0.6 \mathrm{eV} \pm 0.1 \mathrm{eV}$. Our results are in line with the established amphoteric defect model and prove that the instability of the Sb vacancy in $\mathrm{GaSb}$ has a profound role on the native defect concentration in $\mathrm{GaSb}$.
\end{abstract}

DOI: 10.1103/PhysRevB.95.184103

\section{INTRODUCTION}

$\mathrm{GaSb}$ is a narrow-gap compound semiconductor with applications in high speed electronics, thermoelectrics, and long-wavelength optoelectronics. It exhibits uniquely high asymmetry in its mass transport properties: self-diffusion experiments have revealed that $\mathrm{Ga}$ atoms diffuse three orders of magnitude faster through the lattice than $\mathrm{Sb}$ [1]. Compared to self-diffusion in elemental semiconductors [2,3] and other binary III-V compounds [4-7], the diffusivity of $\mathrm{Sb}$ in $\mathrm{GaSb}$ near the melting point is several orders of magnitude lower. The explanation for the unusual behavior has been suggested to lie in the native defect distribution. The Sb vacancy has been proposed to be unstable, easily exchanging sites with a neighboring $\mathrm{Ga}$ atom, resulting in a Ga vacancy $\left(\mathrm{V}_{\mathrm{Ga}}\right)$ and a $\mathrm{Ga}$ antisite $\left(\mathrm{Ga}_{\mathrm{sb}}\right)$. This mechanism would enhance the $\mathrm{Ga}$ diffusion while at the same time suppressing the diffusivity of $\mathrm{Sb}$ due to the lack of Sb-related defects in the lattice.

Another unusual asymmetry in $\mathrm{GaSb}$ is its strong propensity towards p-type conductivity. This type of behavior can be explained as originating from the position of the valence and conduction band edges relative to the Fermi level stabilization energy $\left(\mathrm{E}_{\mathrm{FS}}\right)$ [8]. In $\mathrm{GaSb}$, the valence band essentially coincides with this level, favoring the equilibrium formation of acceptor-type defects [9]. Further, this may lead to an amphoteric nature of charged defects introduced through nonequilibrium processes, as observed in, e.g., GaAs and InN $[8,10]$.

The identity of the acceptor-type defect responsible for the p-type conductivity of nominally undoped $\mathrm{GaSb}$ has been under debate for quite some time [11-22]. Most recent experimental and theoretical work show that $\mathrm{V}_{\mathrm{Ga}}$ and $\mathrm{Ga}_{\mathrm{sb}}$ are the dominant acceptor-type native defects in $\mathrm{GaSb}$ [17,21-23], but their relative importance depends on the crystallization conditions [21-23]. For Czochralski-grown bulk GaSb crystals the concentration of $\mathrm{Ga}$ antisites is an order of magnitude higher than that of the Ga vacancies, making the antisite the

*natalie.segercrantz@aalto.fi main cause for $\mathrm{p}$-type behavior. In epitaxial GaSb the $\mathrm{Ga}$ vacancies play a more significant role.

In this work, we reveal the unstable behavior of the $\mathrm{Sb}$ vacancy by irradiating undoped, $\mathrm{p}$-type GaSb with high-energy protons and performing positron annihilation spectroscopy both ex situ and in situ and subsequently annealing the material in the temperature interval $35-300 \mathrm{~K}$. Both $\mathrm{Ga}$ and $\mathrm{Sb}$ vacancy defects are introduced in the lattice by irradiation at low temperature. At a temperature of approximately $150 \mathrm{~K}$, the $\mathrm{Sb}$ vacancy becomes unstable, undergoing a transition resulting in a $\mathrm{Ga}$ antisite and a $\mathrm{Ga}$ vacancy thereby increasing the acceptor-type defect concentration in GaSb. Our results show that the instability of the Sb vacancy has a clear effect on the native defect distribution in $\mathrm{GaSb}$.

\section{EXPERIMENTAL DETAILS}

The studied material consists of undoped, Czochralskigrown, $\mathrm{p}$-type $\mathrm{GaSb}$ with $\left[\mathrm{Ga}_{\mathrm{Sb}}\right] \approx 10^{17} \mathrm{~cm}^{-3}$ and $\left[\mathrm{V}_{\mathrm{Ga}}\right] \approx$ $10^{16} \mathrm{~cm}^{-3}$ [22]. Positron annihilation spectroscopy is a nondestructive technique especially suitable for studying open-volume defects and negatively charged ions [24]. The positron experiences the absence of a nucleus as a potential well where the antiparticle can get trapped before annihilation. Negative ions can also trap positrons in hydrogen-like Rydberg states. The positron lifetime gives information on the positron trapping states in the crystal. Due to the reduced electron density at vacancy defects, the positron lifetimes are longer compared to the lifetimes of positrons annihilating in a delocalized state in the lattice. Negative ion-like defects produce a lifetime similar to that of the delocalized state in the lattice.

In our experiments, the GaSb samples were mounted in a sandwich setup with the source wrapped in a micrometer thick Al foil, on a copper sample holder in thermal contact with a closed cycle helium cryostat. We used a conventional fast-fast coincidence system with Gaussian timing resolution of 260 ps (FWHM) and a $20 \mu \mathrm{Ci}{ }^{22} \mathrm{NaCl}$ source for the positron lifetime experiments. Prior to analysis, the positron annihilation in the source, in the $\mathrm{Al}$ foil, and as positronium were subtracted from the lifetime data. For the irradiation, a 



defects formation [8]. The phenomenon is strong enough to cause amphoteric instability of donor-type defects such as the $\mathrm{Sb}$ vacancy.

\section{CONCLUSIONS}

In conclusion, we have shown that the $\mathrm{Sb}$ vacancy in $\mathrm{GaSb}$ becomes unstable at temperatures above $150 \mathrm{~K}$ and undergoes a transition resulting in a $\mathrm{Ga}$ antisite and $\mathrm{Ga}$ vacancy. The Sb vacancy activation energy is estimated to be $0.6 \pm 0.1 \mathrm{eV}$, which is comparable to that of the unstable $\mathrm{Si}$ vacancy in $\mathrm{Si}$. The experiments were performed by irradiated undoped, p-type GaSb with high-energy protons and using positron annihilation spectroscopy ex situ as well as in situ and subsequently annealing the samples. Due to the instability of the Sb vacancy, the acceptor-type defect concentration in p-type GaSb is further increased as a result of irradiation. Our results are in agreement with the findings of self-diffusion experiments in $\mathrm{GaSb}$.

\section{ACKNOWLEDGMENT}

We gratefully acknowledge Jukka Viheriälä for performing the mechanical grinding on the GaSb samples.
[1] H. Bracht, S. P. Nicols, W. Walukiewicz, J. P. Silveira, F. Briones, and E. Haller, Nature (London) 408, 69 (2000).

[2] H. Bracht, E. E. Haller, and R. Clark-Phelps, Phys. Rev. Lett. 81, 393 (1998).

[3] H. D. Fuchs, W. Walukiewicz, E. E. Haller, W. Dondl, R. Schorer, G. Abstreiter, A. I. Rudnev, A. V. Tikhomirov, and V. I. Ozhogin, Phys. Rev. B 51, 16817 (1995).

[4] L. Wang, L. Hsu, E. E. Haller, J. W. Erickson, A. Fischer, K. Eberl, and M. Cardona, Phys. Rev. Lett. 76, 2342 (1996).

[5] H. Bracht, M. Norseng, E. E. Haller, K. Eberl, and M. Cardona, Solid State Commun. 112, 301 (1999).

[6] O. Ambacher, F. Freudenberg, R. Dimitrov, H. Angerer, and M. Stutzmann, Jpn. J. Appl. Phys. 37, 2416 (1998).

[7] L. Wang, A. Volk, L. Hsu, E. E. Haller, J. W. Erickson, M. Cardona, T. Ruf, J. P. Silveira, and F. Briones Fernández-Pola, Appl. Phys. Lett. 70, 1831 (1997).

[8] W. Walukiewicz, J. Vac. Sci. Technol. B 5, 1062 (1987); the charge neutrality level (branch point energy) or hydrogen (dangling bond) energy level are similar concepts: W. Jaegermann, Ber. Bunsenges. Phys. Chem. 100, 402 (1996); C. G. Van de Walle and J. Neugebauer, Nature (London) 423, 626 (2003).

[9] K. Alberi and M. A. Scarpulla, Sci. Rep. 6, 27954 (2016).

[10] F. Tuomisto, A. Pelli, K. M. Yu, W. Walukiewicz, and W. J. Schaff, Phys. Rev. B 75, 193201 (2007).

[11] I. Poole, M. E. Lee, I. R. Cleverley, A. R. Peaker, and K. E. Singer, Appl. Phys. Lett. 57, 1645 (1990).

[12] R. Wurschum, W. Bauer, K. Maier, A. Seeger, and H.-E. Schaefer, J. Phys.: Condens. Matter 1, SA33 (1989).

[13] M.-H. Du and S. B. Zhang, Phys. Rev. B 72, 075210 (2005).

[14] C. C. Ling, M. K. Lui, S. K. Ma, X. D. Chen, S. Fung, and C. D. Beling, Appl. Phys. Lett. 85, 384 (2004).

[15] S. K. Ma, M. K. Lui, C. C. Ling, S. Fung, C. D. Beling, K. F. Li, K. W. Cheah, M. Gong, H. S. Hang, and H. M. Weng, J. Phys.: Condens. Matter 16, 6205 (2004).
[16] S. Dannefaer, W. Puff, and D. Kerr, Phys. Rev. B 55, 2182 (1997).

[17] V. Virkkala, V. Havu, F. Tuomisto, and M. J. Puska, Phys. Rev. B 86, 144101 (2012).

[18] J. Mahony, G. Tessaro, P. Mascher, H. Siethoff, and H.-G. Brion, Mater. Sci. Forum 196, 1449 (1995).

[19] C. C. Ling, W. K. Mui, C. H. Lam, C. D. Beling, S. Fung, M. K. Lui, K. W. Cheah, K. F. Li, Y. W. Zhao, and M. Gong, Appl. Phys. Lett. 80, 3934 (2002).

[20] C. C. Ling, S. Fung, C. D. Beling, and W. Huimin, Phys. Rev. B 64, 075201 (2001).

[21] N. Segercrantz, J. Slotte, I. Makkonen, J. Kujala, F. Tuomisto, Y. Song, and S. Wang, Appl. Phys. Lett. 105, 082113 (2014).

[22] J. Kujala, N. Segercrantz, F. Tuomisto, and J. Slotte, J. Appl. Phys. 116, 143508 (2014).

[23] N. Segercrantz, I. Makkonen, J. Slotte, J. Kujala, T. D. Veal, M. Ashwin, and F. Tuomisto, J. Appl. Phys. 118, 085708 (2015).

[24] F. Tuomisto and I. Makkonen, Rev. Mod. Phys. 85, 1583 (2013).

[25] S. Väyrynen, P. Pusa, P. Sane, P. Tikkanen, J. Räisänen, K. Kuitunen, F. Tuomisto, J. Härkönen, I. Kassamakov, E. Tuominen et al., Nucl. Instrum. Methods, Phys. Res. 572, 978 (2007).

[26] J. Slotte, S. Kilpeläinen, F. Tuomisto, J. Räisänen, and A. N. Larsen, Phys. Rev. B 83, 235212 (2011).

[27] F. Agulló-López, C. R. A. Catlow, and P. D. Townsend, Point Defects in Materials (Academic Press, New York, 1988).

[28] K. Thommen, Phys. Rev. 174, 938 (1968).

[29] P. Hautojärvi and C. Corbel, in International School of Physics Enrico Fermi, Course CXXV, edited by A. Dupasquier (IOP Press, Amsterdam, 1993).

[30] F. Tuomisto, K. Saarinen, D. C. Look, and G. C. Farlow, Phys. Rev. B 72, 085206 (2005).

[31] G. D. Watkins, Mater. Sci. Semicond. Process. 3, 227 (2000). 